\title{
Morphological and genetic relationships between wild and domesticated forms of peppers (Capsicum frutescens $\mathrm{L}$. and C. chinense Jacquin)
}

S.I.C. Carvalho ${ }^{1,2}$, C.F. Ragassi ${ }^{2}$, L.B. Bianchetti ${ }^{3}$, F.J.B. Reifschneider ${ }^{4}$, G.S.C. Buso ${ }^{3}$ and F.G. Faleiro ${ }^{1,5}$

${ }^{1}$ Faculdade de Agronomia e Medicina Veterinária, Universidade de Brasília, Brasília, DF, Brasil

${ }^{2}$ Embrapa Hortaliças, Brasília, DF, Brasil

${ }^{3}$ Embrapa Recursos Genéticos e Biotecnologia, Brasília, DF, Brasil

${ }^{4}$ Embrapa Relações Internacionais, Brasília, DF, Brasil

${ }^{5}$ Embrapa Cerrados, Brasília, DF, Brasil

Corresponding author: S.I.C. Carvalho

E-mail: sabrina.carvalho@embrapa.br / sabrinacarvalho.carvalho@gmail.com

Genet. Mol. Res. 13 (3): 7447-7464 (2014)

Received July 22, 2013

Accepted January 10, 2014

Published September 12, 2014

DOI http://dx.doi.org/10.4238/2014.September.12.11

ABSTRACT. Capsicum chinense and C. frutescens peppers are part of the Brazilian biodiversity, and the Amazon basin is the area of greatest diversity for them, especially for that former species. Nevertheless, little is known about their evolutionary history. Aiming to identify genotypes with wild and domesticated characteristics, 30 accessions of the germplasm bank of Embrapa were characterized using morphological descriptors and ISSR molecular markers. Of the 72 primers tested, $42 \%$ showed amplification and produced 136 amplicons with some of the primers, namely $i 7 \mathrm{Pv}$ and $\mathrm{i} 57 \mathrm{Zm}$, allowing the identification of each 
species. ISSR also revealed polymorphisms within a species, especially between domesticated and wild forms. Four wild accessions collected in the Amazon region (CNPH 4315, CNPH 4372, CNPH 4337 and CNPH 4325B) popularly known as "olho-de-peixe" or "olho-de periquito" were molecularly classified as $C$. chinense and showed fruit with similar characteristics as the wild species: upright position, rounded to campanulate shape, small size $(1.0 \mathrm{~cm}$ long and $0.8 \mathrm{~cm}$ wide), average weight of $0.2 \mathrm{~g}$, dark-red color when ripe, easy detachment of calyx and presence of calyx annular constriction (discriminative of C. chinense). The wild form CNPH 4353 known as "malaguetinha" was morphologically and molecularly classified as $C$. frutescens, demonstrating a more preserved morphology in $C$. frutescens than in $C$. chinense. A significant correlation was found between morphological and molecular characterization, and the combination of the two analyses was effective in identifying and classifying the wild forms and contributing to evolutionary studies in the genus.

Key words: Molecular characterization; Domestication; ISSR; Morphological characterization; Diversity; Germplasm bank

\section{INTRODUCTION}

The genus Capsicum comprises about 35 taxa (species and varieties) which, classified into categories according to the level of domestication, corresponds to five domesticated taxa and thirty wild (semi-domesticated and wild) (Bianchetti and Carvalho, 2005). It is believed that the genus Capsicum has been domesticated independently in, at least, three regions: $C$. annuиm L. var. annuиm and C. frutescens $\mathrm{L}$. in Mesoamerica (region between central Mexico and northwestern Costa Rica), C. baccatum L. var. pendulum (Willd.) Eshbaugh and C. pubescens Ruiz \& Pavon in the Andean region, and C. chinense Jacquin in the plains region of tropical South America (Pickersgill, 2007).

The wild ancestors of three species (C. annuum var. annuum, C. baccatum var. pendulum and C. pubescens) have already been identified. However, the evolutionary history of domesticated species of Capsicum is not totally consolidated. The known wild ancestors show upright, bright, small, oval, red, deciduous and spicy fruits, and the region of its natural occurrence matches that of the domesticated forms. On the other hand, little is known about the evolutionary history of $C$. frutescens and $C$. chinense. Some authors comment on the difficulty in determining the wild forms of these species, and Walsh and Hoot (2001) even believe that there is no true form of wild $C$. chinense.

C. annuum, C. chinense, and C. frutescens have been traditionally treated as a "complex" due to their high morphological similarity and genetic proximity. These species have often received undifferentiated treatment even regarding the identification of the possible immediate ancestor (Pickersgill, 1988). Each of these three species, however, possesses at least one unique characteristic that allows its clear distinction. In this sense, the same characteristics should be observed in the wild ancestor as well as the domesticated one. For example, domesticated $C$. annuит var. annuиm and its wild ancestor (C. annuиm var. glabriusculum) distinctively show 
the occurrence of only one flower per branch and white corolla without the presence of stains. Likewise, the likely wild ancestor of domesticated $C$. chinense may show constriction at the base of the calyx (Smith and Heiser, 1951), a discriminative characteristic of this species.

Of the five domesticated taxa, $C$. chinense seems to be the one that has less information especially on the definition of the center of origin and the probable progenitor, although it is evident that the Amazon region (South America) is the center of diversity of this species (Eshbaugh, 1993). However, the first specimens of C. chinense showing the characteristics shared by the wild species of Capsicum and the presence of constriction at the base of the calyx were identified in Roraima (Brazil) by Barbosa et al. (2002). Moreover, in the far northern Brazilian Amazon, indigenous people use $C$. chinense peppers with wild characteristics, which grow naturally in the hills and foothills of north-central and northeastern Roraima and were probably dispersed by birds. Among the indigenous natives, these peppers are grown in their gardens because of their mystical belief in "Curupira" or "Ataí-taí" and were symbolically named "Pimenta do Curupira" or just "pimi'ró" (small pepper, in Macuxi language) (Nascimento Filho et al., 2007).

The domesticated forms of $C$. chinense stand out by their wide morphological variability, expressed in different shapes, sizes, and colors of the fruits, which are generally very spicy and aromatic. Some forms with sweet fruits are also found, such as the "pimenta de bico", very common in the state of Minas Gerais, Brazil. The most popular kinds of pepper of this species are "habanero", "pimenta-de-cheiro", "murupi", "pimenta-de-bico" ("biquinho"), "pimentade-bode", and "cumari-do-Pará" (Ribeiro et al., 2008). In Brazil, "murupi" is the favorite morphological type among the indigenous and non-indigenous people in Roraima State to prepare sauces and "jequitaia" (pepper powder). Murupi fruits are elongated, with a rough surface and yellow or red color when ripe, weigh less than $4.5 \mathrm{~g}$, and show a characteristic aroma and high pungency (Barbosa et al., 2010), which may reach values over 220,000 SHU (Scoville Heat Unit) (Ribeiro et al., 2008). This species is popular throughout the tropical region and widely used to give flavor and pungency in the Caribbean cuisine (Moses and Umaharan, 2012).

C. frutescens, in general, is characterized by having small, conical, upright, spicy fruits, with thin fruit wall, generally red when ripe and with no calyx annular constriction between calyx and pedicel (Carvalho et al., 2006). However, variations in the shape, position, size, and color of fruits have already been observed in populations of $C$. frutescens, and they are therefore classified as domesticated. The most common example, previously considered as the only domesticated form for a long time, is the popular so-called "Tabasco pepper" (Pickersgill, 1971), cultivated in the United States. Baral and Bosland (2004) reported the existence of the accessions of $C$. frutescens showing big, pendant, and persistent fruits, suggesting the existence of other domesticated forms, besides cultivated "Tabasco".

The geographical distribution of $C$. frutescens occurs from the lowlands of southeastern Brazil to Central America and the Antilles, in the Caribbean. In Brazil, it is possible to observe part of the variations mentioned especially related to size and deciduousness of the fruits, which can vary from very small and deciduous (slight persistence between pedicel and fruit) to large and persistent ones, popularly known as "malaguetinha", "malagueta", and "malaguetão".

Collection expeditions in the Amazon region, since the 1990s, made it possible to obtain populations with characteristics capable of discriminating the species $C$. chinense (especially the presence of calyx annular constriction between calyx and pedicel) and $C$. fru- 
tescens (especially elongated, thin-wall fruits, with no calyx annular constriction between calyx and pedicel, as well as characteristics related to the category of wild species (upright position, small size, dark-red color when ripe, and easy detachment of calyx). These accessions enriched the Germplasm Bank of Capsicum (GB) of the Empresa Brasileira de Pesquisa Agropecuária (Embrapa), and from this bank, it was possible to find five specimens with wild characteristics, with one being recorded as $C$. frutescens and four as $C$. chinense.

The appropriate characterization of these accessions provides an indication of the degree of domestication and human interference. Only one part of the "gene pool" is selected in the domestication process (genetic bottleneck) in each selection cycle. Thus, this process is always associated with a reduction in the genetic diversity of the selected population (Eyre-Walker et al., 1998). Thus, the identification and incorporation of wild accessions in a breeding program can cover part of the lost genetic variability and allow, through genetic combinations, the emergence of new individuals that are better adapted, productive, and disease-resistant, among other characteristics.

Since 1994, the use of ISSR (inter-simple sequence repeats), based on SSR (simple sequence repeats) has become considerably more accessible (Zietkiewicz et al., 1994) for genetic studies and genetic improvement of species of agricultural interest. The ISSR technique involves the amplification of DNA by PCR, using a single primer composed of a microsatellite sequence, anchored in the $3^{\prime}$ or $5^{\prime}$ region for two to four arbitrary nucleotides (Gonzales et al., 2005). The use of this technique overcomes the limitations of prior knowledge of the sequences of microsatellites. It is a simple method, with relatively low cost when compared to other markers, and it provides high reproducibility and shows a high number of polymorphic fragments. The ISSR markers are dominant, and the amplification product is not known, which means they are random markers as in RAPD (random amplified polymorphic DNA). However, ISSR markers are more reliable, because the primers are larger and the annealing temperature is higher, which provides a greater specificity (Bornet and Branchard, 2001). ISSR have been used for several purposes, such as phylogenetic inferences (Dogan et al., 2007), evaluation of genetic diversity (Aguilera et al., 2011), and studies of species complexes (Michelan et al., 2012), among others.

The present study aimed to carry out a morphological and molecular characterization of wild and domesticated forms, comparing them to a representative sample of other accessions of the GB. We also attempted to determine the accuracy of pre-existing taxonomic classification and report on the existence of genotypes with wild characteristics belonging to the species $C$. frutescens and C. chinense.

\section{MATERIAL AND METHODS}

\section{Genetic material}

A sample of 30 accessions of the GB of Embrapa was used in this study, including five accessions with wild characteristics collected in the Amazon region (Table 1). The sample comprised nine accessions registered in the GB as belonging to the species $C$. frutescens, seventeen classified as $C$. chinense, two accessions of $C$. baccatum species (one $C$. baccatum var. praetermissum and one C. baccatum var. pendulum) and, finally, two accessions of C. annuum (one C. annuиm var. glabriusculum and one C. anпиит var. annuит). 


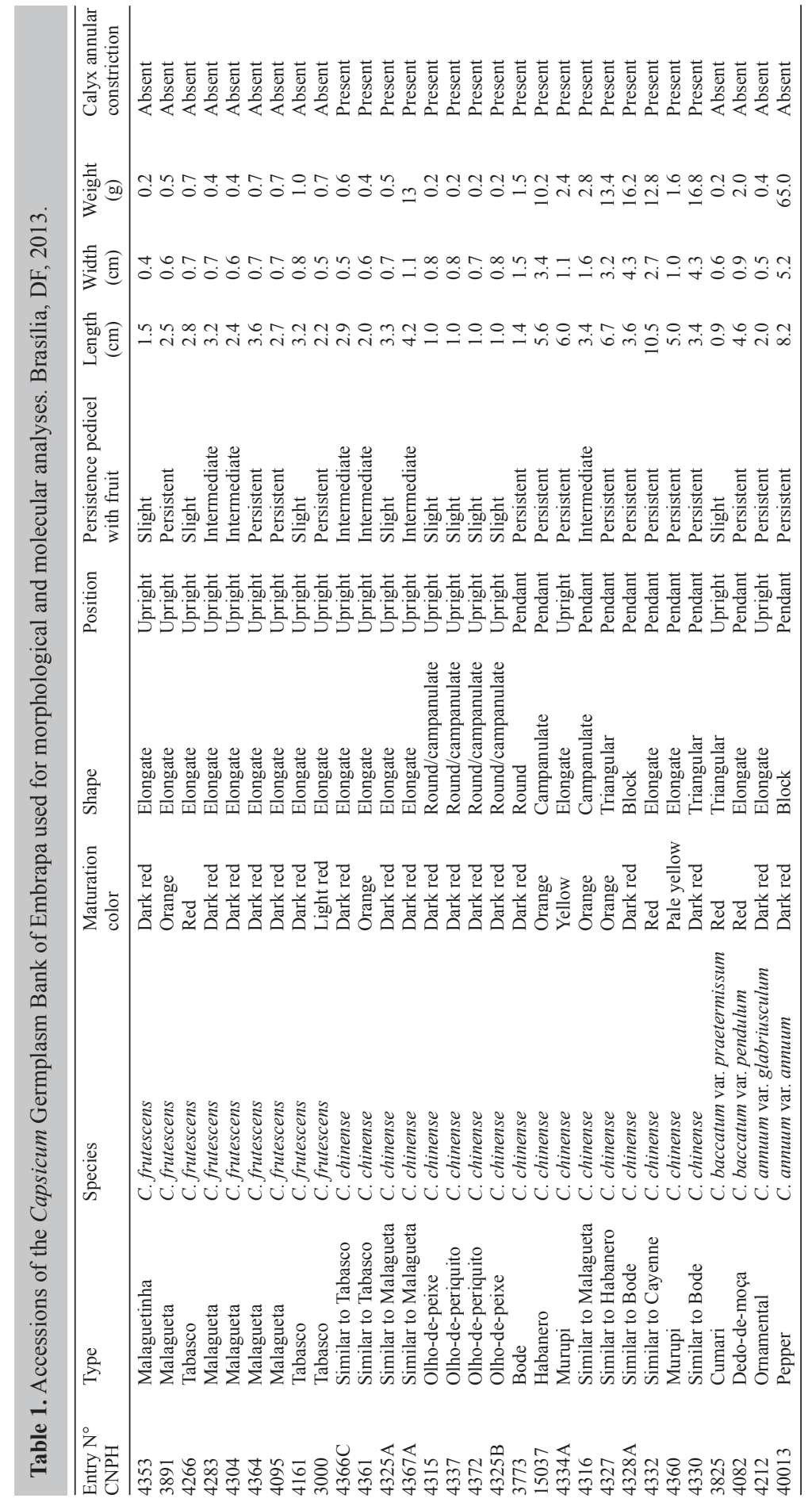




\section{Morphological characterization}

The seeds of the accessions were germinated in polystyrene trays containing organic substrate in greenhouses with anti-aphid screen and, after 45 days, five plants of each accession were transplanted to soil, also in a greenhouse, arranged in rows spaced $1.5 \mathrm{~m}$, with $0.60 \mathrm{~m}$ between plants. The morphological characterization of the plants was then carried out 90 days after sowing, using eight internationally recommended descriptors for Capsicum (IPGRI - International Plant Genetic Resources Institute, 1995), all related to fruit: maturation color, shape, position, persistence between pedicel and fruit, length, width, weight, and presence of calyx annular constriction between calyx and pedicel. Five plants per accession were characterized. These descriptors related to the characteristics of the fruits were chosen because they provide an indication of the degree of domestication that has occurred in the genotypes of this study, since the fruit is the focus in the selection. The species were identified by a key to identify species and domesticated and semi-domesticated varieties of the genus Capsicum in Brazil (Ribeiro et al., 2008).

On the basis of the means of the morphological descriptors, coefficients of genetic dissimilarity were obtained for each pair of accessions according to DEMP (standardized average Euclidean distance). The genetic dissimilarity matrix generated was subjected to cluster analysis by UPGMA (unweighted pair-group method using arithmetic average) and represented by a dendrogram. The Genes software was used to perform these analyses. The time to stop the clustering algorithm (cutoff value of the dendrogram) to set the number of groups was defined according to the average genetic distance between genotypes using the NTSys pc 2.1 software. The graphic dispersion was also carried out according to the multidimensional scales through the main coordinates, using the SAS and Statistica software.

\section{Molecular characterization}

Leaves of each accession were collected and genomic DNA extracted using the $2 \%$ CTAB method, with scale modifications (Boiteux et al., 1999). The DNA concentration was estimated by $1 \%$ agarose gel electrophoresis, comparing the fluorescence intensities of each sample stained with ethidium bromide with different lambda DNA standards. Each sample was then diluted to $3.0 \mathrm{ng} / \mu \mathrm{L}$.

The diversity among the accessions was evaluated using twelve ISSR primers developed for beans (i1Pv to i12Pv) (Acampora et al., 2007) and sixty for corn (i1Zm to i60Zm) (Gianfilippi, 2006). For the polymerase chain reaction (PCR), a 13- $\mu \mathrm{L}$ mix was prepared. This mix contained $2.59 \mu \mathrm{L}$ MilliQ water, $1.3 \mu \mathrm{L} 10 \mathrm{X}$ buffer, $0.25 \mu \mathrm{L} 50 \mathrm{mM} \mathrm{MgCl}_{2}, 1.3 \mu \mathrm{L}(2.5$ $\mathrm{mM}$ x 4) dNTPs, $1.3 \mu \mathrm{L} 2.5 \mathrm{mg} / \mathrm{mL}$ BSA, $3 \mu \mathrm{L} 1.2 \mathrm{mM}$ primer, $0.26 \mu \mathrm{L} 5 \mathrm{U} / \mu \mathrm{L}$ Taq polymerase and $3 \mu \mathrm{L} 3 \mathrm{ng} / \mu \mathrm{L}$ genomic DNA. The ISSR amplification reactions occurred as follows: $94^{\circ} \mathrm{C}$ for $5 \mathrm{~min}$ for denaturation, 35 cycles of $1 \mathrm{~min}$ at $94^{\circ} \mathrm{C}, 1 \mathrm{~min}$ at $56^{\circ} \mathrm{C}$ for annealing and $1 \mathrm{~min}$ at $72^{\circ} \mathrm{C}$, and a final extension at $72^{\circ} \mathrm{C}$ for $10 \mathrm{~min}$.

The amplification reactions were carried out on a $1.5 \%$ agarose gel, stained with ethidium bromide $(0.2 \mu \mathrm{g} / \mathrm{mL})$, for separation of ISSR fragments. Gels were visualized and photographed under ultraviolet light.

The polymorphic bands were then classified according to their absence (0) and presence (1), and matrices based on the complement of the Jaccard coefficient were created, used for comparison between the accessions. On the basis of genetic distances, a dendrogram was 
constructed using UPGMA and the consistency of clusters analyzed by 1000 bootstrap simulations, using the Genes software, and the adjustment of the dissimilarity matrix with the respective dendrogram was estimated by the cophenetic correlation coefficient (r), using the NTSys pc 2.1 software. Using this same software, the average global dissimilarity between the accessions was calculated and, at this value (cutoff of the dendrogram), a dotted line was drawn in the graph, serving as a reference for the formation of groups of accessions. The graphic dispersion based on multidimensional scales was carried out with the method of the main coordinates, using the SAS and Statistica software. Finally, the significance of the association between distance matrices obtained by ISSR and morphological characters was estimated on the basis of the Pearson correlation coefficient and $t$-test, also using the Statistica software.

\section{RESULTS}

\section{Morphological characterization}

The eight morphological descriptors used for characterization detected variation between the accessions evaluated. From these descriptors, cluster analyses were performed and the corresponding dissimilarity dendrogram was constructed (Table 1; Figure 1).

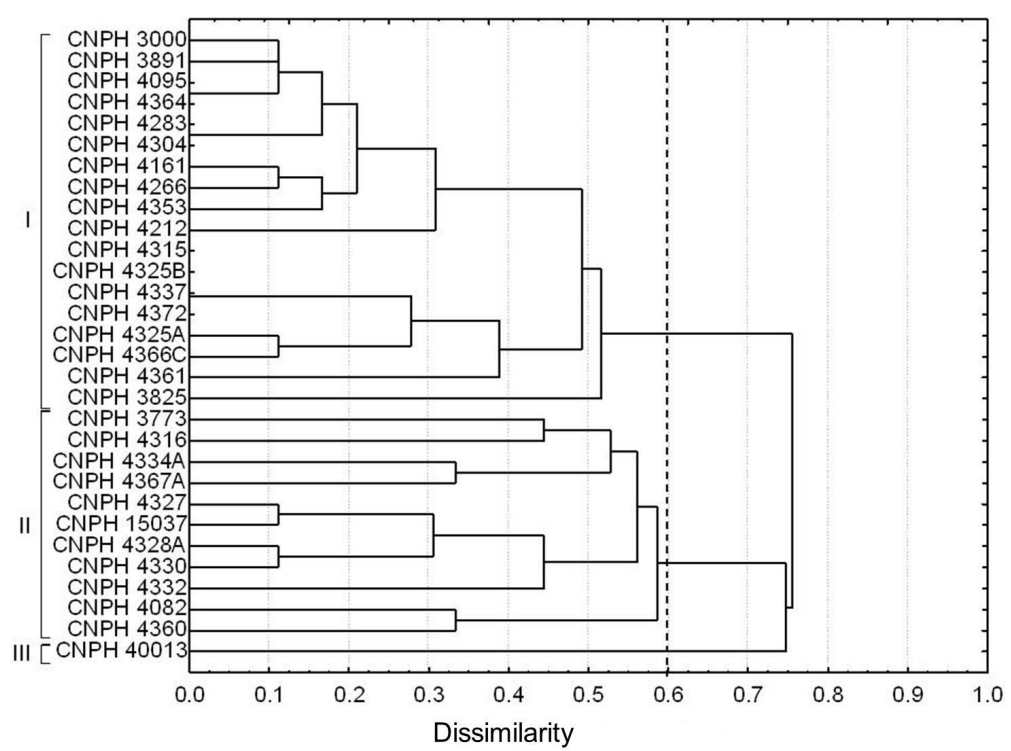

Figure 1. Dendrogram with accessions of Capsicum spp built on multicategorical data obtained from morphological descriptors.

In the dendrogram generated from the characterization using morphological descriptors (Figure 1), three groups were formed when considering the cutoff value corresponding to the global average dissimilarity between the accessions $(=0.60)$. Group I was the largest and comprised 18 accessions of the four species studied. Group II was formed by 11 accessions of the two species $C$. chinense and C. baccatum var. pendulum, and group III was formed by only 
one accession, corresponding to C. апnиит var. annuит (bell pepper).

Group I comprised all the accessions with wild characteristics, of the four species evaluated, C. frutescens (accession CNPH 4353), C. chinense (accessions CNPH 4315, CNPH 4325B, CNPH 4372, and CNPH 4337 Figure 2), C. annuum var. glabriusculum (CNPH 4212), and C. baccatum var. praetermissum (CNPH 3825). Among these accessions, the four wild individuals of $C$. chinense appeared to be very close to each other, indicating great morphological similarity of the fruits: upright position, rounded to campanulate shape, small size, (1.0 $\mathrm{cm}$ long and $0.8 \mathrm{~cm}$ wide), average weight of $0.2 \mathrm{~g}$, dark-red color when ripe, easy detachment of calyx (deciduous fruits), favoring removal and, possibly, the dissemination of the seeds. The presence of a calyx annular constriction between calyx and pedicel was also verified, this characteristic being discriminative of $C$. chinense.

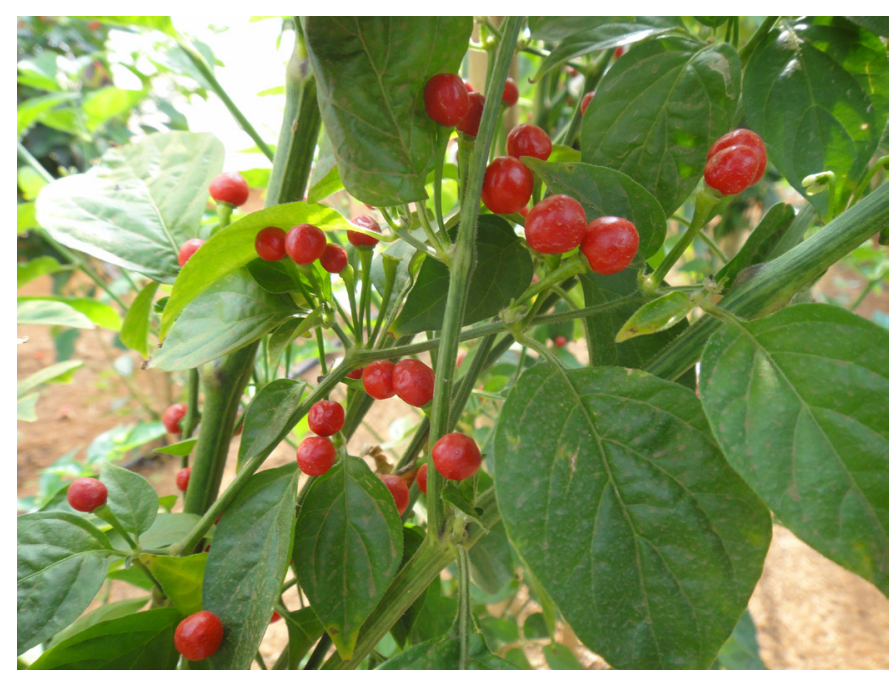

Figure 2 Capsicum chinense with wild characteristics known as "Olho-de-peixe", accession CNPH 4315.

All accessions of $C$. frutescens studied were clustered in Group I. The accession $\mathrm{CNPH} 4353$, known as "malaguetinha", was grouped together with the two domesticated accessions evaluated of this species (CNPH 4161 and CNPH 4266), which are cultivars of Tabasco chili pepper sold in Brazil by seed companies. Four descriptors showed similar results between domesticated and wild accessions of $C$. frutescens: upright fruits, elongated shape, slight persistence of pedicel with fruit, and absence of calyx annular constriction between calyx and pedicel. Variation was seen for the other descriptors. The color of the fruits when ripe was dark red in CNPH 4353 and CNPH 4161 and red for the accession CNPH 4266. Length, width, and weight of the fruits were lower in the wild accession CNPH $4353(1.5 \mathrm{~cm}, 0.4 \mathrm{~cm}$, and $0.2 \mathrm{~g}$, respectively), whereas the two domesticated accessions (CNPH 4161 and $\mathrm{CNPH}$ 4266) produced fruits weighing over $0.7 \mathrm{~g}$ and measuring $3.0 \mathrm{~cm}$ long and $0.7 \mathrm{~cm}$ wide.

Yet, in this same group, specimens with wild characteristics of C. annuum and C. baccatum were placed together: the accession CNPH 4212, an ornamental plant identified as $C$. annuum var. glabriusculum (wild form of $C$. annuum) and the accession CNPH 3825, identified as C. baccatum var. praetermissum (considered a wild form of C. baccatum). Both acces- 
sions showed upright fruits, dark-red color when ripe, elongated (CNPH 4212) to triangular (CNPH 3825) shape, measuring from $0.9 \mathrm{~cm}(\mathrm{CNPH} 3825)$ to $2 \mathrm{~cm}(\mathrm{CNPH} 4212)$ long and 0.5 $\mathrm{cm}$ wide and weight ranging from $0.2 \mathrm{~g}$ (CNPH 3825) to $0.4 \mathrm{~g}(\mathrm{CNPH} 4212)$.

Group II was formed by accessions that showed typical characteristics of domesticated plants, belonging to species $C$. chinense (CNPH 3773, CNPH 4316, CNPH 4334A, CNPH 4367A, CNPH 4327, CNPH 15037, CNPH 4328A, CNPH 4330, CNPH 4332, and CNPH 4360) and C. baccatum var. pendulum (CNPH 4082). Likewise, group III was composed of a domesticated accession of $C$. annuиm var. annuит (CNPH 40013).

The accessions of $C$. chinense and $C$. baccatum with typical traits of domesticated plants showed sharp differences related to the wild specimens of the same species, such as presence of pendant fruits (the fruits are under or protected by the leaves and are barely visible to birds), non-deciduous (persistent), length and width more than 2 and $1.5 \mathrm{~cm}$, respectively, weight from 2 to $17 \mathrm{~g}$, as well as different shapes (rectangular, triangular, campanulate, rounded, and elongated) and fruit colors when ripe (yellow, pale yellow, orange and red).

Group III was formed by the only domesticated individual of C. annuum (CNPH 40013). This accession was different from the other ones studied, displaying big, dark-red fruits that had the greatest width and weight among the accessions evaluated $(5.2 \mathrm{~cm}$ and $65 \mathrm{~g}$, respectively).

The morphological variability between the accessions, stratified per species, was also represented in a scatter plot (Figure 3), which suggested the formation of at least three separate groups, partially corresponding to the species studied. The largest group consisted of $C$. chinense accessions, which was isolated from other species. However, the group consisting predominantly of $C$. frutescens included at their extremities accessions of $C$. annuum and $C$. baccatum. The third group corresponded to two accessions of different species, one C. annuum and one C. baccatum.

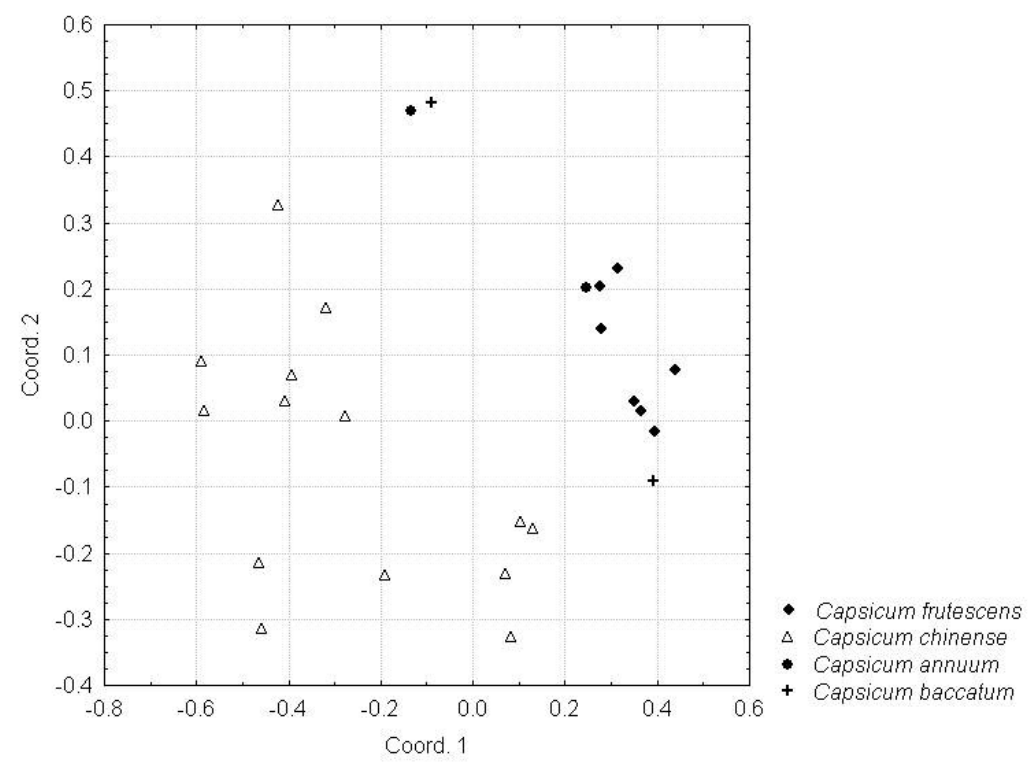

Figure 3. Dispersion of accessions of Capsicum spp obtained from multicategorical analysis of morphological descriptors. 


\section{Molecular characterization}

Of the 72 ISSR primers tested, $30(42 \%)$ showed amplification for the accessions analyzed and all of them showed polymorphism, producing a total of 136 polymorphic amplicons, with an average of 4.5 polymorphic amplicons per primer. These primers allowed the identification of polymorphism among all the species analyzed. Some of them, such as i7Pv and i57Zm (Figure 4), could differentiate the species C. annuum, C. baccatum, C. chinense, and $C$. frutescens, and therefore, they could be used to help in their identification.

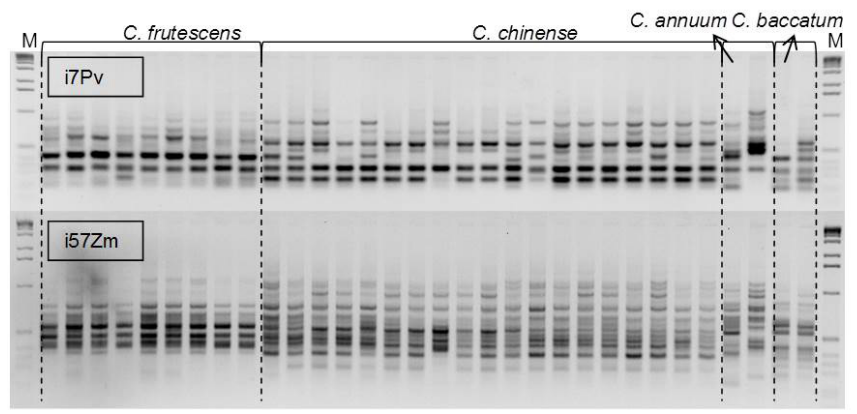

Figure 4. Polimorfisms between and in the species of genus Capsicum verified through application of two ISSR primers (i7Pv and i57Zm); Lane $M=$ molecular marker of molecular weight 1-kb Ladder $^{\circledR}$ (Invitrogen ${ }^{\circledR}$ ).

On the basis of the pattern revealed by 136 polymorphic amplicons, grouping of accessions and construction of the corresponding similarity dendrogram were carried out (Figure 5). The distances between the accessions and their distribution, stratified by species, can also be observed in the dispersion plot (Figure 6).

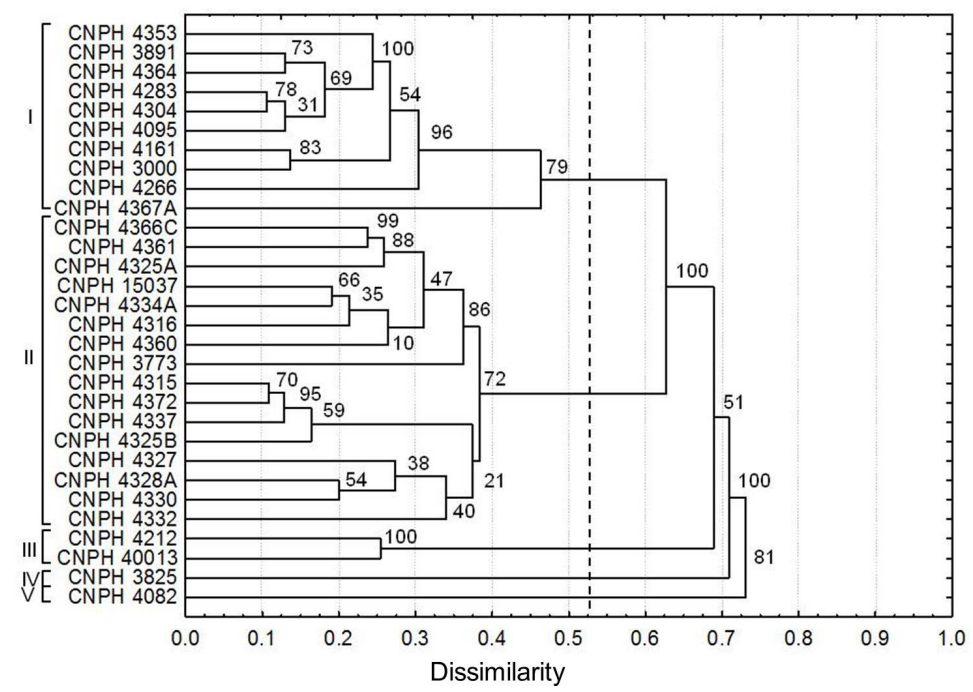

Figure 5. Dendrogram with accessions of Capsicum spp built on binary data obtained through molecular markers type ISSR. 


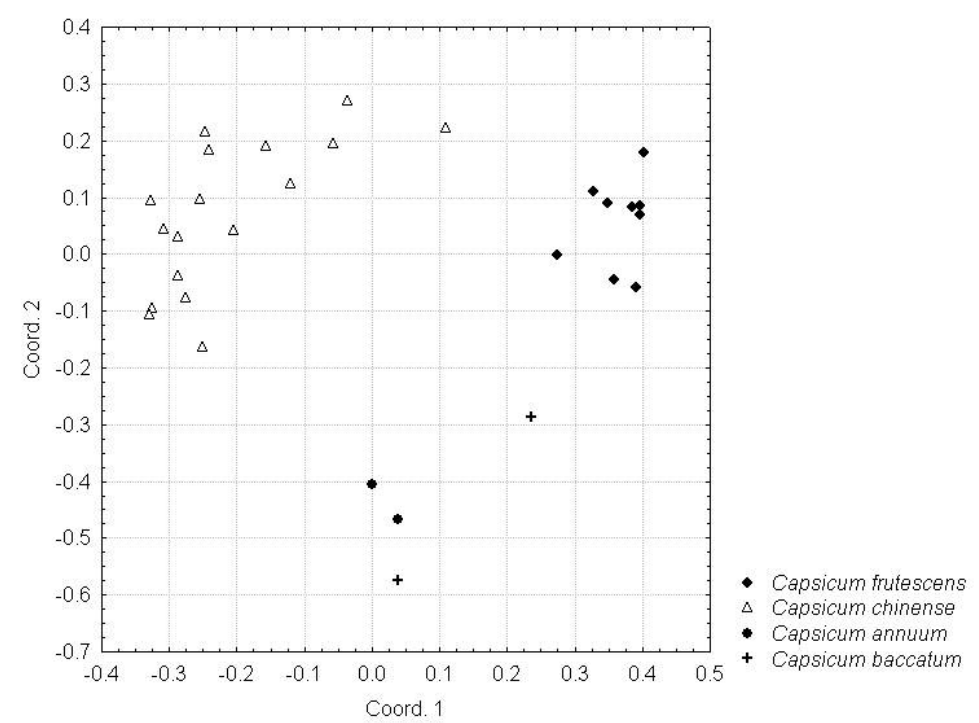

Figure 6. Dispersion of accessions of Capsicum spp obtained from binary data of molecular markers type ISSR.

The correlation between a matrix of co-phenetic values and the similarity matrix was 0.94 , pointing out an excellent fit between the matrix and the plot. Five groups were formed considering the cutoff value corresponding to the global average dissimilarity between the accessions (0.53), considering that two of these groups, IV and V, were formed only by one accession and corresponded to the varieties $C$. baccatum var. praetermissum and C. baccatum var. pendulum, respectively. Group III was formed by two accessions of the same species, one being $C$. annuum var. glabriusculum and the other $C$. annuиm var. annuum. The largest groups, I and II, comprised 10 and 16 accessions and corresponded to the species $C$. frutescens and C. chinense, respectively.

The accessions showing wild characteristics were, in general, grouped with other accessions of the same species. The only exception occurred with the species C. baccatum, in which the domesticated and wild specimens formed exclusive groups and did not group together with any other accession. In $C$. chinense, a subgroup was formed, with a dissimilarity coefficient of 0.37 in relation to the nearest accession, inside the group formed by the species.

Finally, the correlation between the morphological and molecular analysis was verified $(\mathrm{r}=0.56)$. This value was highly significant $(\mathrm{P}<0.01)$ by the $t$-test, but intermediate in magnitude, indicating that the analyses were correlated but did not show exactly the same groups.

\section{DISCUSSION}

In this study, morphological characterization allowed the separation of the wild forms and the domesticated accessions of three species of Capsicum (C. chinense, C. annuum, and C. baccatum). However, separation was not so evident between the wild and domesticated forms of $C$. frutescens (Figure 1). C. frutescens showed a highly conserved morphology among the accessions, and since only eight descriptors were used and all of them related to the fruit, it 
was possible that the accuracy of the analysis was low and that this accounted for the inability to separate the wild and the domesticated forms.

Interestingly, all accessions of $C$. frutescens studied are found in Group I. A plausible explanation would be that forms of the species show a highly conserved morphology (when compared to other species of the genus) and show fruit traits (size, position, and color) typical of wild species (Walsh and Hoot, 2001). For this reason, authors like Jett (1973) even proposed $C$. frutescens as the likely ancestor of the other domesticated species.

The differences between wild and domesticated forms of $C$. chinense were clearly distinguished in this study. Moreover, the morphological characteristics identified in the wild accessions studied are shared with the wild species in general, that is, the fruits are upright, bright, small (generally smaller than $2 \mathrm{~cm}$ ), oval shaped, red when ripe, easily detached from the plant (deciduous), and generally spicy (Pickersgill, 1969; 1971).

All these characteristics are associated with the attractiveness of the fruit and seed dispersion carried out by birds. The presence and the size of the beak of birds select the deciduous, small, and rounded-shape fruits, and the absence of teeth prevents the mechanical damage of the seeds by chewing. Besides, birds can distinguish the colors and are attracted to the plants with upright, bright, and red fruits. Finally, the birds are neurologically insensitive to capsaicin. Capsaicin is a secondary metabolite responsible for the pungency of peppers which has no repellent effect on beneficial seed dispersers such as birds (Tewksbury and Nabhan, 2001).

The characteristics found exclusively in domesticated plants are not normally present in nature, and their presence is possibly related to the process of domestication, in which the important characteristics for humans are selected, hampering the traits that represent competitive advantages for the plants in a natural environment. It is probable that the wild accessions studied have preserved characteristics such as production of small, upright fruits, positioned above the leaves, with easy detachment and intense red color when ripe, because these traits mean competitive advantages regarding seed dispersal by birds.

Even when considering the morphological changes induced by the domestication process, it is expected that the domesticated species (or in the process of domestication) share some distinctive characteristics with their wild relatives. For example, C. baccatum var. pendulum (domesticated) shows distinctively white flowers with yellow or golden spots at the base of the corolla lobes, as its wild ancestor (C. baccatum var. baccatum). C. pubescens shows distinctive flowers with lilac corollas, as its wild ancestor (C. eximium).

The results of this study showed accessions of domesticated $C$. chinense discriminated by the presence of calyx annular constriction between calyx and pedicel, which was also found in the wild forms (CNPH 4315, CNPH 4325B, CNPH 4372, and CNPH 4337).

When considering the value of global average dissimilarity as a reference for defining groups in the dendrogram of molecular markers (Figure 5), separation between the wild and cultivated accessions could be noticed only in C. baccatum.

It was observed, however, that three specimens identified as wild $C$. chinense in the morphological characterization (CNPH 4315, CNPH 4372, and CNPH 4337) were placed in group II of the molecular characterization, which corresponded to this species, but these three accessions were clustered in a highly cohesive subgroup ( $95 \%$ bootstrap coefficient), demonstrating that these accessions are closer to each other than to the domesticated specimens. Nevertheless, when considering the accession CNPH 4325B, a less cohesive subgroup was formed ( $59 \%$ bootstrap coefficient), with high similarity even though this accession was considered 
identical to the other three specimens in the morphological characterization.

Assuming an ancestry relationship between wild and domesticated, the sympatric occurrence between elements of different categories, that is, the existence of a coincidence or partial overlap between the distribution area of the domesticated forms and the area of occurrence of the wild forms closely related to those domesticated ones, corroborates this conclusion. Thereby, Eshbaugh (1970) on the basis of morphology and results of crosses, proposed the relationship of ancestry between C. baccatum var. pendulum (domesticated) and C. baccatum var. baccatum (wild ancestor) and pointed out the lowlands of Bolivia as a probable region where the process of domestication for this species could have occurred. Pickersgill (1971) on the basis of morphological and chromosomal evidence presented the relationship of ancestry between $C$. annuum var. annuиm (domesticated) and C. annuиm var. glabriusculum (wild ancestor) and identified Mexico as a probable region where the process of domestication for this species could have occurred. Eshbaugh (1976) on the basis of morphological, chemotaxonomic and cross evidence considered that $C$. eximium and $C$. cardenasii represent the "complex" of ancestor species which was the origin of the domesticated species $C$. pubescens and identified the lands of moderate elevation of Bolivia where the process of domestication for this species took place.

The wild forms of $C$. chinense evaluated in the present study were obtained in the Brazilian Amazon region, in the area of the geographic distribution of the respective domesticated species and probable region where the process of domestication for the species occurred. The evidence of genetic proximity with the domesticated forms of this species was provided in the molecular characterization.

C. chinense shows a better adaptation to hot humid conditions than do the other domesticated species of Capsicum. In this way, some authors think that they might have been domesticated in the lowlands of east of the Andes and spread in association with cassava (Pickersgill, 1969).

The Amazon covers half of South America, but because of lack of data, it is many times neglected when the origin and diversity of crops are discussed. According to Clement (1999), this lack of attention is not due to a lack of cultivated plants by the indigenous people in preColombian times, but because of the result of the post-Colombian population collapse in the basin. He also reported that the Amazon could have had 4 to 5 million people when the Europeans arrived. These people cultivated or managed at least 138 plant species in 1492. Many of these agricultural genetic resources were human artifacts that required human intervention for maintenance, meaning that they were in an advanced stage of domestication. Consequently, a relationship between the decline of Amazonian indigenous populations and the loss of genetic resources in the centuries immediately following the European conquest was noticed.

During the domestication process, when humans assume the role as the main agent of selection, they are able to interfere in the process of natural evolution of a species, weakening the link between wild and domesticated species. Besides, many species can represent intermediate forms between wild and domesticated (Ribeiro et al., 2008).

C. frutescens shows wild species characteristics (shape, color, and fruit position) and isozyme and morphological patterns similar to those of $C$. chinense. Thus, it has been considered by some authors (e.g., Eshbaugh et al., 1983) as the ancestor form of $C$. chinense. However, the present study and those of Baral and Bosland (2004) and Albrecht et al. (2012) do not agree with this hypothesis, the results of which clearly show the existence of two distinct species, on the basis of morphological, phylogenetic, and reproduction evidence. 
Both CNPH 4353 ("malaguetinha"), indicated as the wild form of C. frutescens in this study, and other traditionally cultivated accessions of $C$. frutescens showed similar results for some morphological descriptors (especially regarding shape, position, and color of fruits). These results are according to the ones of DeWitt and Bosland (2009) when they concluded that $C$. frutescens is a species that has the most preserved morphology, with few differences in shape, size, and color of fruits when compared to C. annuum, C. baccatum or C. chinense. These authors suggested that the absence of selection may be related to the low genetic variability of $C$. frutescens compared to the other species of the genus. It is important to point out that the morphological diversity of the fruits is guided by humans, meaning that the differences in size, shape, and color of the fruit result from selection by humans based on the fruits, which are harvested for the following cultivation. Possibly, the uniformity of the $C$. frutescens characteristics is a reflection of the low genetic variability, thus a high degree of homozygosity can be noticed. Another interpretation of the low variability in $C$. frutescens would be that the selection has been very intense and restrictive, resulting in reduced variability of the species.

In general, wild and domesticated populations differ in several characteristics that are targets of human selection, although some domesticated plants are indistinguishable from the wild ones. However, the allele frequency governing the characters subjected to the human selection presumably differs, which characterizes, at least, one incipient domestication or semidomestication (Pickersgill, 2007).

In morphological characterization (Figure 1), all accessions with characteristics of wild species, regardless of the taxonomic classification of species, were grouped in group I. In this group, it is observed that CNPH 4212 (C. annuum var. glabriusculum) appears as a sister group of all other accessions of $C$. frutescens, demonstrating a certain proximity of the species C. annuum and C. frutescens, while CNPH 3825 (C. baccatum var. praetermissum) appears as the sister group to all other accessions in group I, demonstrating a much greater dissimilarity and independence from all accessions of the group (including accessions of $C$. annuum, $C$. frutescens, and $C$. chinense). These data are consistent with the recent literature which indicates independent evolutionary lines among different complexes of related species: complex $C$. annuиm (composed of the species $C$. annuиm var. annuиm, $C$. annuиm var. glabriusculum, C. frutescens, $C$. chinense, and $C$. galapagoense); complex $C$. baccatum $(C$. baccatum var. pendulum, $C$. baccatum var. baccatum, $C$. baccatum var. praetermissum, and $C$. tovarii ); and complex C. pubescens (C. pubescens, $C$. eximium, and $C$. cardenasii) (Ince et al., 2010; Albrecht et al., 2012).

The study also demonstrated that in molecular characterization, the components of group $C$. annuum, $C$. chinense, and $C$. frutescens, appeared to be genetically close to each other and distinct from subgroup C. baccatum, corroborating the morphological analysis of group I. The species C. frutescens (group I) and C. chinense (group II) appeared to be closer to each other (similarity $=0.37$ ) with a bootstrap coefficient of $100 \%$, followed by $C$. annuum (group III; similarity $=0.31$ ) and $C$. baccatum, the most distinct related to the groups formed (group IV and V, similarity $=0.29$ and 0.27 , respectively). These results corroborate those already reported in the literature based on morphology (Pickersgill et al., 1979) and with the use of molecular techniques (Walsh and Hoot, 2001; Buso et al., 2002; Tam et al., 2009; Ince et al., 2010; Albrecht et al., 2012), among others.

It is important to point out that the varieties $C$. baccatum var. praetermissum (group IV) and C. baccatum var. pendulum (group V) showed, between them, low genetic similarity 
(0.26), demonstrating the high genetic distance between varieties hypothetically belonging to the same species (C. baccatum).

The question regarding the inclusion of varieties of $C$. baccatum within the same species, despite the low similarity between them, lasted until the study of Kochieva et al. (2004), who used molecular tools AFLP (amplified fragment length polymorphisms), RAPD and ISSR to determine the genetic relationship between species and varieties of Capsicum and showed results which support the recognition of $C$. praetermissum as an autonomous species and not another variety of $C$. baccatum. The conclusion drawn by Kochieva et al. (2004) had already been reported by Buso et al. (2002) analyzing chloroplast DNA, and more recently, by Albrecht et al. (2012). Moreover, the same observation is also pointed out in the present study, in which the low similarity seen between $C$. baccatum var. praetermissum and C. baccatum var. pendulum would justify the discrimination of different species.

Due to the proximity of the two species $C$. chinense and $C$. frutescens, accessions with intermediate phenotypes make it difficult to identify the species when the classification is based exclusively on morphological data, since the discriminative characters for the two species may appear in the same individual and also because of the influence of environmental factors. The molecular information contributes to the evidence of the differences between these two species (Baral and Bosland, 2004). The close relationship between $C$. frutescens and $C$. chinense was even found by Thul et al. (2012), who determined flower characteristics shared by the two species, besides their proximity at the genotype level.

In this study, the accession CNPH 4367A was initially classified as $C$. chinense on the basis of morphological characterization. However, when the molecular characterization was carried out, this accession (CNPH 4367A) was included in group I of $C$. frutescens (Figure 5). When considering only the $C$. frutescens group, this accession was shown to be the most divergent. In fact, the morphological characteristics of the accession place it in an intermediate or undefined condition between the two species, which may represent an intermediate stage in the evolutionary path of differentiation of the two species, or even a hybrid resulting from the cross-fertilization between the two species. Similar results were obtained in the study of Tam et al. (2009) when using the SSAP (sequence-specific amplification polymorphism) technique and evaluating the genetic structure of 86 accessions of seven species of Capsicum. Those authors reclassified one accession of $C$. frutescens as $C$. chinense on the basis of the analyses. According to Carvalho et al. (2006), it is possible that gene flow occurs between varieties and even between different species of the genus, due to a certain rate of allogamy (or cross-pollination), favored by different rates of compatibility. According to Baral and Bosland (2004), the cultivar Greenleaf Tabasco offers an excellent example of an intermediate phenotype and represents an introgressive hybridization and not an intraspecific variation. This cultivar was developed by interspecific hybridization between $C$. frutescens and C. chinense followed by repeated backcrosses for $C$. frutescens.

The correlation between molecular and morphological analyses carried out in this study was highly significant, although it was of intermediate magnitude. This confirms the reliability of information obtained using both methods independently, but also demonstrates the importance of performing both analyses together to characterize the accessions in a germplasm bank. Morphological characteristics do not always clearly represent the genetic distance, so the morphological analysis tends to be more superficial and influenced by the environment. Molecular analysis, however, shows a more detailed description and it is faithful to the real 
genetic distance, allowing the maximum exploitation of the diversity of the bank. However, as a negative point, molecular characterization does not provide, by itself, information about characteristics of interest for breeding, such as stress resistance and productivity. Thus, the combination of morphological and molecular analyses, as carried out in this study, is suggested for complete and detailed characterization of germplasm banks aimed at plant breeding.

A great number of important points aimed at the identification and use of a wild ancestor of a crop can be studied. In cultural terms, a wild ancestor reveals what were the available resources in a given region at a given time, and part of the human "needs" that led them to domesticate it. In biological terms, it is possible to map the current geographical distribution, infer about the past distribution and map the spread of the species after domestication, identify the centers of diversity and domestication, identify which changes are associated with domestication, and establish the degree of relatedness or relationship of ancestry, among others. One shared characteristic among almost all, if not all, domesticated plants is a drastic reduction in the genetic variability during and after the process of domestication. Thus, the development of measures aimed at the conservation and use of such genetic resources is fully justified, since the incorporation of a wild ancestor in a breeding program can recover part of the lost genetic variability, facilitating the development of genotypes for specific conditions of biotic and abiotic stresses, which would entail a qualitative and quantitative step for the domesticated crop.

Finally, the results showed that the combination of morphologic and molecular characterization was effective and useful to identify and classify the wild forms of $C$. frutescens and $C$. chinense. Through molecular analysis, four specimens with wild characteristics (CNPH 4315, CNPH 4372, CNPH 4337 and CNPH 4325B) were classified as $C$. chinense and showed similar morphological characteristics as the wild species. It is still possible that these accessions collected in the Amazon basin, considered the largest diversity area of $C$. chinense, share the same morphological characteristics of the wild ancestors of this species. In the molecular analysis, the wild form CNPH 4353 was classified as C. frutescens. However, the accessions with domesticated characteristics were not distinguished. These results will help evolutionary studies of the genus, for more detailed analyses of genetic diversity and clarification of phylogenetic relationships between accessions in the context of the GB.

\section{ACKNOWLEDGMENTS}

Research supported by Universidade de Brasília (UnB), Empresa Brasileira de Pesquisa Agropecuária (Embrapa), and CNPq.

\section{REFERENCES}

Acampora A, Ciaffi M, Pace C, Paolacci AR, et al. (2007). Pattern of variation for seed size traits and molecular markers in Italian germplasm of Phaseolus coccineus L. Euphytica 157: 69-82.

Aguilera JG, Pessoni LA, Rodrigues GB and Elsayed AY (2011). Genetic variability by ISSR markers in tomato (Solanum lycopersicon Mill). Rev. Bras. Ciênc. Agrár. 6: 243-252.

Albrecht E, Zhang D, Saftner RA and Stommel JR (2012). Genetic diversity and population structure of Capsicum baccatum genetic resources. Genet. Resour. Crop. Evol. 59: 517-538.

Baral JB and Bosland PW (2004). Unraveling the species dilemma in Capsicum frutescens and C. chinense (Solanaceae): a multiple evidence approach using morphology, molecular analysis, and sexual compatibility. J. Amer. Soc. Hort. Sci. 129: 826-832.

Barbosa RI, Luz FJF, Nascimento Filho HR and Maduro CB (2002). Pimentas do gênero Capsicum cultivadas em Roraima, 
Amazônia Brasileira. I. Espécies domesticadas. Acta Amazon. 32: 177-192.

Barbosa RI, Mourão Júnior M and Luz FJF (2010). Morphometric patterns and preferential uses of Capsicum peppers in the State of Roraima, Brazilian Amazonia. Hortic. Bras. 28: 477-482.

Bianchetti LB and Carvalho SIC (2005). Subsídios à Coleta de Germoplasma de Espécies de Pimentas e Pimentões de Gênero Capsicum (Solanaceae) In: Fundamentos para a Coleta de Germoplasma vegetal (Walter BMT and Cavalcanti TB, eds.). Embrapa Recursos genéticos e Biotecnologia, Brasília, 355-385.

Boiteux LS, Fonseca MEN and Simon PW (1999). Effects of plant tissue and DNA purification method on randomly amplified polymorphic DNA-based genetic fingerprinting analysis in carrot. J. Am. Soc. Hortic. Sci. 124: 32-38.

Bornet B and Branchard M (2001). Nonanchored Inter Simple Sequence Repeat (ISSR) markers: reproducible and specific tools for genome fingerprinting. Plant Mol. Biol. Rep. 19: 209-215.

Buso GSC, Amaral ZPS, Bianchetti LB and Ferreira ME (2002). Análise de sequências de DNA cloroplástico de espécies do gênero Capsicum. Boletim Técnico da EMBRAPA/EPAGRI 3: 1-21.

Carvalho SIC, Bianchetti LB, Ribeiro CSC and Lopes CA (2006). Pimentas do gênero Capsicum no Brasil. Documentos Embrapa Hortaliças 94: 1-49.

Clement CR (1999). 1492 and the loss of amazonian crop genetic resources. I. The relation between domestication and the human population decline. Econ. Bot. 53: 188-202.

DeWitt D and Bosland PW (2009). The Complete Chile Pepper Book. A Gardener's Guide to Choosing, Growing, Preserving, and Cooking. 1st edn. Timber Press, London.

Dogan B, Duran A and Hakki EE (2007). Phylogenetic analysis of Jurinea (Asteraceae) species from Turkey based on ISSR amplification. Annal. Bot. Fennici 44: 353-358.

Eshbaugh WH (1970). A biosystematic and evolutionary study of Capsicum baccatum (Solanaceae). Brittonia 22: 31-43.

Eshbaugh WH (1976). Genetic and biochemical systematic studies of chile peppers (Capsicum - Solanaceae). Bull. Torrey Bot. Club 102: 396-403.

Eshbaugh WH, Smith PG and Nickrent DL (1983). Capsicum tovarii (Solanaceae), a new species of pepper from Peru. Brittonia 35: 55-60.

Eshbaugh WH (1993). History and Exploitation of a Serendipitous New Crop Discovery. In: New Crops (Janick J and Simon JE, eds.). Wiley, New York, 132-139.

Eyre-Walker A, Gaut RL, Hilton H, Feldman DL, et al. (1998). Investigation of the bottleneck leading to the domestication of maize. Proc. Natl. Acad. Sci. U. S. A. 95: 4441-4446.

Gianfilippi F (2006). Studio Della Diversita Molecolare in Popolazioni Locali Italiane di Lenticchia (Lens culinaris Medik) Tramite Marcatori ISSR. Tesi de Láurea Agrária. Università degli studi della Tuscia, Tuscia.

Gonzales A, Wong A, Delgado-Salinas A and Papa R (2005). Assessment of inter simple sequence repeat markers to differentiate sympatric wild and domesticated populations of common bean (Phaseolus vulgaris L.). Crop Sci. 45: 606-615.

Ince AG, Karaca M and Onus AN (2010). Genetic relationships within and between Capsicum species. Biochem. Genet. 48: 83-95.

IPGRI - International Plant Genetic Resources Institute (1995). Descriptors for Capsicum (Capsicum spp.). IPGRI, Rome. Jett SC (1973). Comment of Pickersgill's "Cultivated plants as evidence for cultural contacts". Am. Antiq. 38: 223-225.

Kochieva EZ, Ryzhova NN, van Dooijeweert W and Boukema IW (2004). Assessment of Genetic Relationships in the Genus Capsicum Using Different DNA Marker Systems. Proceedings of the XIIth EUCARPIA Meeting on Genetics and Breeding of Capsicum and Eggplant, Noordwijkerhout.

Michelan VS, Trevisan R, Silva CRM, Souza RF, et al. (2012). Morphological and genomic characterization of Rhynchospora tenuis complex (Cyperaceae) and its taxonomic implications. Rodriguesia 63: 775-784.

Moses M and Umaharan P (2012). Genetic structure and phylogenetic relationships of Capsicum chinense. J. Amer. Soc. Hortic. Sci. 137: 250-262.

Nascimento Filho HR, Barbosa RI and Luz FJF (2007). Pimentas do gênero Capsicum cultivadas em Roraima, Amazônia brasileira: II. Hábitos e formas de uso. Acta Amazon. 37: 561-568.

Pickersgill B (1969). Archaeological record of chili-peppers (Capsicum spp) and sequence of plant domestication in Peru. Am. Antiq. 34: 54-61.

Pickersgill B (1971). Relationships between weedy and cultivated forms in some species of chili peppers (Genus Capsicum). Evolution 25: 683-691.

Pickersgill B (1988). The genus Capsicum - a multidisciplinary approach to the taxonomy of cultivated and wild plants. Biologisches Zentralblatt 107: 381-389.

Pickersgill B (2007). Domestication of plants in the Americas: insights from mendelian and molecular genetics. Annals Bot. 100: 925-940.

Pickersgill B, Heiser CB and McNeill J (1979). Numerical Taxonomic Studies on Variation and Domestication in Some 
Species of Capsicum. In: Solanaceae I. The Biology and Taxonomy of the Solanaceae (Hawkes JG, Lester RN and Skelding AD, eds.). Academic Press, New York, 679-700.

Ribeiro CSC, Lopes CA, Carvalho SIC, Henz GP, et al (2008). Pimentas Capsicum. 1st edn. Embrapa Hortaliças, Brasília. Smith PG and Heiser CB (1951). Taxonomic and genetic studies on the cultivated peppers, Capsicum annuum L. and Capsicum frutescens L. Amer. J. Bot. 38: 362-368.

Tam SM, Lefebvre V, Palloix A, Sage-Palloix AM, et al. (2009). LTR-retrotransposons Tnt1 and T135 markers reveal genetic diversity and evolutionary relationships of domesticated peppers. Theor. Appl. Genet. 119: 973-989.

Tewksbury JJ and Nabhan GP (2001). Seed dispersal. Directed deterrence by capsaicin in chilies. Nature 412: 403-404.

Thul ST, Darokar MP, Shasany AK and Khanuja SP (2012). Molecular profiling for genetic variability in Capsicum species based on ISSR and RAPD markers. Mol. Biotechnol. 51: 137-147.

Walsh BM and Hoot SB (2001). Phylogenetic relationships of Capsicum (Solanaceae) using DNA sequences from two noncoding regions: the chloroplast atpB-rbcL spacer region and nuclear waxy introns. Int. J. Plant Sci. 162: 14091418.

Zietkiewicz E, Rafalski A and Labuda D (1994). Genome fingerprinting by simple sequence repeat (SSR)-anchored polymerase chain reaction amplification. Genomics 20: 176-183. 